\title{
Oncological outcomes after endoscopic removal of malignant colorectal polyps
}

\author{
Bruno Moreira Gonçalves ${ }^{1}$, Vasco Fontainhas ${ }^{1}$, Ana Célia Caetano ${ }^{1,2,3}$, Aníbal Ferreira ${ }^{1,2,3}$, Raquel \\ Gonçalves $^{1}$, Pedro Bastos ${ }^{1}$ and Carla Rolanda ${ }^{1,2,3}$
}

${ }^{I}$ Department of Gastroenterology. Hospital Braga. Portugal. ${ }^{2}$ Life and Health Sciences Research Institute (ICVS). School of Health Sciences. University of Minho. Braga, Portugal. ${ }^{3} I C V S / 3 B$ 's - PT Government Associate Laboratory. Braga/Guimarães, Portugal

\begin{abstract}
Objective: malignant colorectal polyp, defined by submucosally invasive adenocarcinoma, is the earliest form of clinically relevant colorectal cancer (CRC). After endoscopic resection additional surgery may be necessary, although decision criteria remain debatable. The objective of this study was to assess oncologic outcomes in terms of locoregional disease and to identify areas of improvement that may facilitate patients' management.

Methods: retrospective study of 40 patients with T1 CRC endoscopically resected between 2007 and 2012. Clinicopathological features were assessed and correlated with residual disease (RD), defined as presence of adenocarcinoma in intestinal wall and/ or lymph nodes.

Results: thirty-one patients underwent surgery while 9 were followed-up. After surgery, RD was confirmed in 15 (48.4\%) patients: $8(53.3 \%)$ wall disease, 5 (33 \%) nodal metastasis, and $2(13.3 \%)$ with both. No recurrence was detected in the follow-up group. The characteristics of the lesions that were associated with DR were sessile configuration $(p=0.03)$, the degree of differentiation G3 ( $p$ $=0.01)$ and intercepted/indeterminate margins $(p=0.01)$. Twenty-two patients were operated because of inadequate evaluation, mainly due to piecemeal resection, and half of them were disease free. Postoperative complications were found in 9 (30 \%) patients, mainly anastomotic leakage that was associated with rectum anterior resection ( $p=0.03)$.

Conclusions: surgery should be considered in the presence of any risk factor for residual disease, while follow-up can be offered in low risk settings. Was also demonstrated a clear need for technical improvement in endoscopic resection and pathology evaluation in order to prevent unnecessary surgeries.
\end{abstract}

Key words: Malignant polyp. Postoperative complications. Residual disease. Risk factors. Submucosal invasion.

\footnotetext{
Received: 12-04-2013
}

Accepted: 11-09-2013

Correspondence: Bruno Moreira Gonçalves. Serviço de Gastrenterologia. Hospital de Braga. Sete Fontes - São Victor. 4710-243 Braga, Portugal e-mail: brunommgoncalves@gmail.com

\section{INTRODUCTION}

More than $95 \%$ of colorectal cancer (CRC) arises from adenomas throughout the recognized adenoma-adenocarcinoma sequence $(1,2)$. Therefore, during CRC screening the adenomatous lesion is the target, and its resection by endoscopic polypectomy has shown to reduce the risk of advanced adenomas and future colorectal cancer $(3,4)$.

With progressive technique refinements the endoscopic therapy became safe and effective to treat the majority of colorectal precursor lesions, whether they are pedunculated, sessil or flat, independently of size. By principle, polyps should be resected en bloc to provide adequate evaluation of resection margins and possible tumor spreading. If this can be easily achieved in pedunculated or smaller polyps, for sessil lesions larger than $2 \mathrm{~cm}$, piecemeal endoscopic mucosal resection (EMR) is the commonly used technique. However, endoscopic submucosal dissection (ESD) has been used as an effective mode of achieving en bloc resection of large, sessile and flat lesions, although it has higher perforation rates, greater procedure duration, and requires a demanding learning curve (5-8).

Several terms have been used to describe carcinoma that is restricted to the epithelial layer without invasion into the lamina propria (high-grade dysplasia, carcinoma "in situ", intraepithelial neoplasia) (6). Intramucosal carcinoma is a carcinoma characterized by invasion into the lamina propria. In all these situations endoscopic resection can offer a curative treatment (9). However, when the carcinoma breaches the muscularis mucosa and spreads to the submucosa

Gonçalves BM, Fontainhas V, Caetano AC, Ferreira A, Gonçalves $R$, Bastos P, Rolanda C. Oncological outcomes after endoscopic removal of malignant colorectal polyps. Rev Esp Enferm Dig 2013;105:454-461. 
(where the lymphatic and vascular structures are), the polyp is considered to have become malignant with potential risk for lymph nodes or distant sites metastasis $(6,10,11)$. These lesions represent the earliest form of clinically relevant CRC, corresponding to $0.5-8 \%$ of the endoscopic resected adenomas, and in this case additional surgery may be necessary to ensure complete tumor clearance $(12,13)$.

Several studies have suggested that certain features may be valuable predictors of lymph node metastasis or persistent residual tumor after endoscopic resection. These factors include deep submucosal invasion, poor or undifferentiation, lymphovascular invasion, and positive resection margins $(6,10,13-15)$. Nevertheless, the identification of those patients remains a challenge, in fact even in the presence of high-risk features residual disease is noted in $15-20 \%$ of the operated cases, and nodal disease is detected in a smaller proportion (13). Thus, around $84 \%$ of patients may be undergoing significant morbidity due to unnecessary surgical interventions after endoscopic resection (14).

In this sequence, we propose ourselves to perform a retrospective analysis on the cumulative experience in the management of malignant colorectal polyps resected endoscopically in our department. Besides studying the clinicopathological features of patients and tumors, this work aims: a) to evaluate the oncologic outcomes in terms of locoregional disease (colorectal wall residual or recurrent tumor, and lymph node metastasis); and b) to study predictors and areas of work improvement that may facilitate patient selection for surgery versus surveillance.

\section{PATIENTS AND METHODS}

We studied retrospectively all patients with malignant colonic polyps treated by endoscopic resection at the Gastroenterology Department of the Hospital Braga, between January 2007 and November 2012. Data was collected through a complete review of patients' clinical, endoscopic, histologic and surgical reports. This study was approved by the Human Research Ethics Committee of Hospital Braga.

The main inclusion criteria was a histologically proven submucosal invasive adenocarcinoma in a flat, sessile or semi-pedunculated lesion, or in case of pedunculated polyps a submucosal deep invasion larger than $3,000 \mu$ from the neck (Haggitt level 2) or a free margin inferior to $2,000 \mu(6)$, resected in our department and subsequently submitted to surgery or under follow-up for at least 24 months. Patients who did not accomplish the former or received a macroscopically incomplete polypectomy were excluded from this study.

Endoscopic resection was decided by the operator after macroscopic criteria assessment, as lifting sign, morphology, friability, induration, and ulceration, according to Paris Classification (16). Depressed (0-IIc) and ulcerated (0-III) lesions weren't removed and the patients were referred to surgery. Technical approach included almost always the injection of saline solution into the submucosa and the lift-and-cut technique. EMR was performed preferably en bloc, when impossible, the endoscopist performed a piecemeal EMR and applied argon plasma coagulation (APC) in the visible vessels and the borders of some cases.

\section{Tumors characteristics}

Tumors were evaluated in order to macroscopic and microscopic parameters. Macroscopically they were classified according to: a) dimension; b) morphology (polypoid -pedunculated and semi-pedunculated; non-polypoid- sessile and flat lesions) (16); and c) location (rectum, left colon and right colon, separated in the mid transverse). Specimens were microscopically characterized for: a) resection margin status; b) histological type; c) grade of differentiation; and d) presence of perineural or lymphovascular (lymphatic and venous) invasion. Resection margins were defined as: Tumor-free or complete (if malignant cells were not present within $100 \mu$ ) and incomplete margins (whenever the previous requirement was not met -intersected by diathermy effect or undetermined, when the exact margin and orientation could not be assessed, due to piecemeal resection). According with the regular classification of intestinal-type adenocarcinoma in four grades (6), for stage of differentiation we considered two groups: Well-moderately differentiated (grade I-II) and poorly differentiated carcinoma (grade III-IV). Regarding vascular invasion, it was defined by the presence of cancer in an endothelia-lined channel surrounded by smooth-muscular cells. Lymphatic invasion was characterized by the presence of tumor cells within a true endothelial-lined channel in the absence of red blood cells. Ideally, the depth of submucosal invasion should be assessed in non-pedunculated lesions by Kikuchi classification (Sm1, Sm2 and Sm3) (17). However, besides deep invasion in pedunculated polyps, this measure was not available in our pathological reports, because the majority of the lesions underwent piecemeal resection, and we believe also due to the lack of experience in this evaluation.

\section{Clinical approaches and outcomes}

All the patients were proposed for surgical resection, due to an inadequate histological evaluation (incomplete margins or absence of deep invasion evaluation), or the presence of unfavorable risk factors (lymphovascular invasion or poor differentiation). Patients who underwent surgical resection received regular oncologic orientation and follow-up (FU). Patients that refused surgery or had prohibitive comorbidities were included in a follow-up scheme that, besides clinical evaluation, included annual measurement of carcinoembryonic antigen (CEA) levels and abdominal CT scan (colon cancers) or pelvic CT/MRI (rectal cancers). Control colonoscopy was performed at 
three, six and twelve months after endoscopic resection and then annually repeated. In order to achieve valuable outcomes in FU patients, a minimal duration of 24 months was required. This was based in previous studies reporting time to recurrence up to 22 months (9).

Surgical and FU groups were both evaluated for oncological outcomes, mainly locoregional disease (wall tumor and/or local lymph node metastasis) and distant metastasis. Residual disease was defined as adenocarcinoma present in colorectal wall in the segmentectomy sample, and recurrent disease as adenocarcinoma identified by colonoscopy during the follow-up program. Lymph node metastasis (LNM) were considered whenever present in the resected specimen or detected in radiologic FU.

\section{Statistical analysis}

Categorical variables were summarized using proportions and assessed by Chi-squared and Fisher's exact tests. Continuous variables were summarized using mean (+/$\mathrm{SD})$ and median range. T-test was used to compare continuous variables. All tests were two sided and the level of significance was set at $p<0.05$. Statistical analysis was made on SPSS 20.0 for Windows ${ }^{\circledR}$.

\section{RESULTS}

Since 2007, 63 patients were diagnosed with malignant colonic polyps after endoscopic resection in our depart- ment. Three of those patients were immediately excluded because they had macroscopically incomplete polypectomy. Of the total 60 patients, 31 underwent complementary surgical resection, while 29 were included in the FU program, either by older age and/or co-morbidities (23 patients) or surgery refusal (6 patients). Twenty patients in the FU were excluded because 3 of them did not accomplished the adequate FU, 10 had a FU considered insufficient for conclusions (less than 24 months), and 7 were lost during the FU program. Figure 1 represents the flowchart of the patients' management.

Finally the population of this study included 40 patients, in which 29 were male and 11 female $\left(\sigma^{\top} / Q=2.6 / 1\right)$. Mean age was 64.3 years (range $36-90$ years) and the mean tumor size was $23.6 \mathrm{~mm}$ (range $10-50 \mathrm{~mm}$ ). En bloc resection was performed in 25 patients, while 15 patients received endoscopic piecemeal resection. The characteristics of the removed tumors are listed in table I.

Patients who received complementary surgical resection had a mean age of 61.7 years. All of them had lymph node dissection and the mean number of retrieved lymph nodes was 8.7. Colorectal segmentectomy was performed in 22 of the patients (71\%) -by laparoscopy in 14 and open approach in 8 patients- rectum anterior resection (RAR) was performed in 9 patients $(29.0 \%)$. Postoperative complications were found in $9(30 \%)$ patients, 2 anastomotic hemorrhages $(22.2 \%)$ and 7 anastomotic leakages $(77.8 \%)$. Leakage is a major concern and in our patients it was statistically associated with RAR procedure $(\mathrm{p}=$ 0.034). Colostomy (definitive or temporary) was performed in 3 patients who had post-RAR anastomotic leakage.

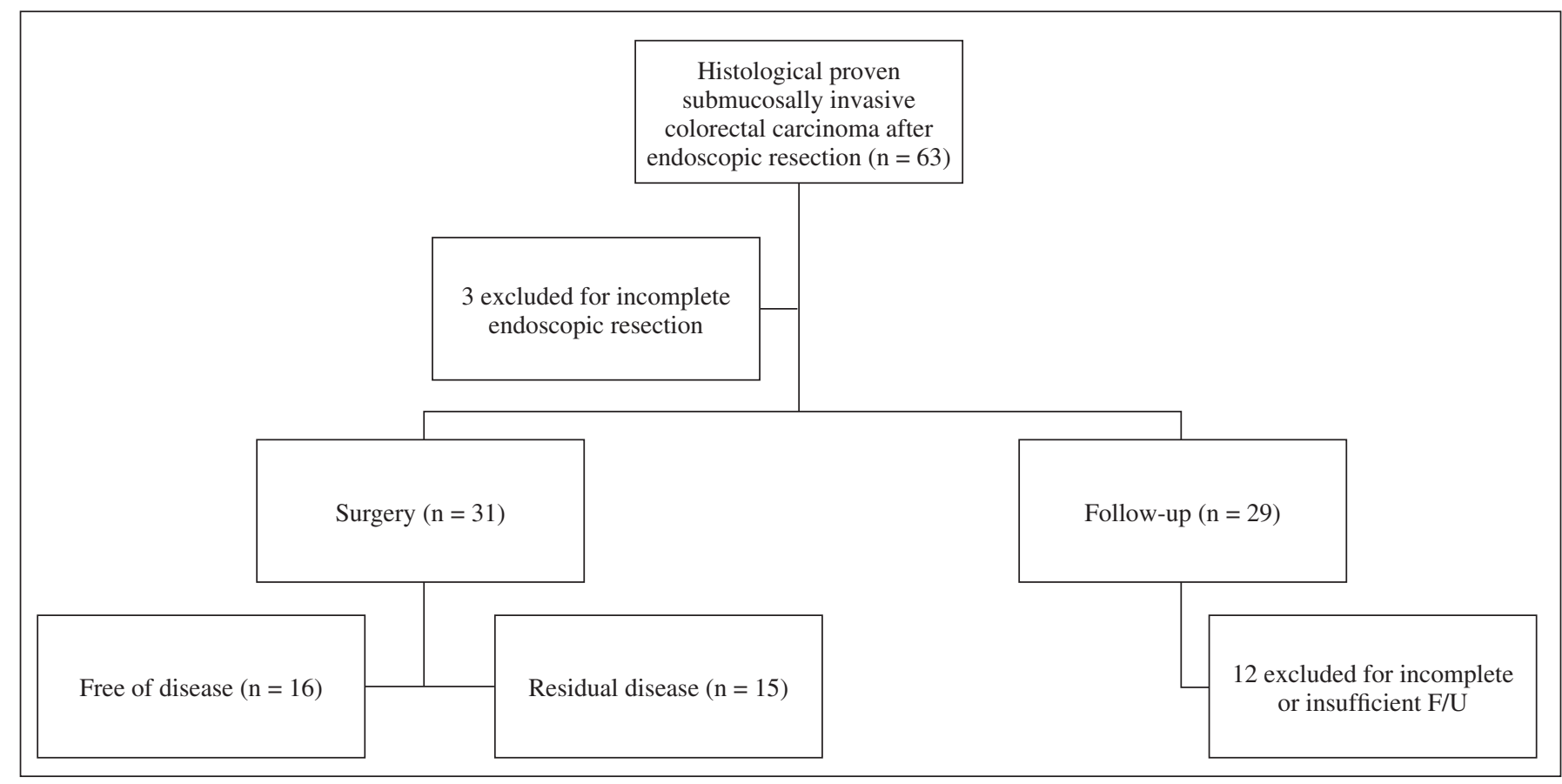

Fig. 1. Management of 63 patients with histologic proven submucosally invasive colorectal carcinoma after endoscopic resection. 
Table I. Characteristics of tumors after endoscopic resection

\begin{tabular}{|c|c|c|c|}
\hline Variables & $\begin{array}{c}\text { Total } n(\%) \\
n=40\end{array}$ & $\begin{array}{c}\text { Subsequent } \\
\text { surgery } n=31\end{array}$ & $\begin{array}{c}\text { Follow-up } \\
\quad n=9\end{array}$ \\
\hline \multicolumn{4}{|l|}{ Macroscopic } \\
\hline Size mm (range) & $23.4(10-50)$ & $24.7(10-50)$ & $19.1(15-25)$ \\
\hline \multicolumn{4}{|l|}{ Location } \\
\hline Rectum & $12(30.0)$ & $10(32.3)$ & $2(22.2)$ \\
\hline Left colon & $22(55.0)$ & $18(58.1)$ & $4(44.4)$ \\
\hline Right colon & $6(15.0)$ & $3(9.7)$ & $3(33.3)$ \\
\hline \multicolumn{4}{|l|}{ Configuration } \\
\hline Polypoid & $16(40.0)$ & $11(35.5)$ & $5(55.6)$ \\
\hline Non-polypoid & $24(60.0)$ & $20(64.5)$ & $4(44.4)$ \\
\hline \multicolumn{4}{|l|}{ Microscopic } \\
\hline \multicolumn{4}{|l|}{ Margins } \\
\hline Complete & $16(40.0)$ & $8(25.8)$ & 8 (88.9) \\
\hline Intersected & $9(22.5)$ & $9(29.0)$ & $0(0.0)$ \\
\hline Undetermined & $15(37.5)$ & $14(45.2)$ & $1(11.1)$ \\
\hline \multicolumn{4}{|l|}{ Differentiation } \\
\hline Well & $33(82.5)$ & $25(80.6)$ & $8(88.9)$ \\
\hline Moderate & $5(12.5)$ & $4(12.9)$ & $1(11.1)$ \\
\hline Poorly & $2(5.0)$ & $2(6.5)$ & $0(0.0)$ \\
\hline \multicolumn{4}{|c|}{ Angiolymphatic invasion } \\
\hline Absent & $35(87.5)$ & $26(83.9)$ & $9(100.0)$ \\
\hline Present & $5(12.5)$ & $5(16.1)$ & $0(0.0)$ \\
\hline \multicolumn{4}{|l|}{ Venous invasion } \\
\hline Absent & $38(95.0)$ & $29(93.5)$ & $9(100.0)$ \\
\hline Present & $2(5.0)$ & $2(6.5)$ & $0(0.0)$ \\
\hline
\end{tabular}

In surgically resected group, global residual disease (in colon wall and/or lymph nodes) was noted in 15 patients $(48.4 \%)$. In 8 patients $(53.3 \%)$, disease was exclusively limited to the colonic wall, 5 patients $(33.3 \%)$ presented nodal metastasis and 2 patients $(13.3 \%)$ presented both colonic wall residual lesion and lymph node metastasis. In the follow-up after surgery, no patients had recurrence.

Patients who did not undergo additional surgery and that accomplished the inclusion criteria had a median follow-up period of 36.1 months (range, 24-52 months). The mean age was 73.1 years. Only one of these 9 patients had a risk factor for residual disease (undetermined margin). During the follow-up period, no evidence of recurrence was detected.

Outcomes according to patients and tumors characteristics on univariate analysis are summarized in table II. It can be seen that gender $(\mathrm{p}=0.04)$, polyp configuration $(\mathrm{p}=0.03)$, differentiation $(\mathrm{p}=0.02)$ and margin status $(p=0.02)$ were factors for colonic wall disease. No significant correlations have been established for lymph node metastasis. Multivariate analysis showed that margin status was the only independent risk factor for wall disease $(\mathrm{p}=$ 0.02 ; $\mathrm{OR}=0.09 ; 95 \% \mathrm{CI}=0.01-0.6$ ).

Looking for the classical risk factors of residual disease, besides the submucosal invasion which depth was not available for study, we found that incomplete margins, presence of lymphovascular invasion and poor differentiation were the main risk factors for residual disease and, therefore, indications for subsequent surgery. Twenty-one patients $(52.5 \%)$ had only one risk factor for residual disease and 6 patients $(15 \%)$ had simultaneously two risk factors. Risk factors for residual disease and resultant outcomes are summarized in table III. Univariate analysis showed that the presence of only one risk factor is determinant of poor outcome $(p=0.08)$ while the presence of no risk factor is strongly associated with lower incidence of residual disease $(p=0.13)$.

When evaluating the features that determined the decision for surgery we find out that 22 patients underwent surgical resection because of inadequate initial specimen assessment -undetermined margins, intercepted margins, lack of depth submucosal evaluation in some cases of en bloc resection- and in 11 of those patients $(50 \%)$ there was no residual disease at the resection specimen. There was no significant difference between rectum or colon distribution, as it is presented in table IV. However $80 \%$ of patients that besides en bloc resection and complete margins were submitted to surgical resection (due to lacking of depth submucosal evaluation), and $41 \%$ of patients with intercepted or undetermined margins (mainly related to piecemeal resection) had no residual disease.

\section{DISCUSSION}

Endoscopic resection affords patients with the typical advantages of minimally invasive procedures, but in $\mathrm{T} 1$ (tumor invading submucosa) colorectal cancers it should be used selectively because of decreased certainty regarding oncologic outcomes when local recurrence or LNM is considered $(14,18)$. Many studies attempted the definition of potential predictors for locoregional residual disease, however the indications for subsequent colectomy versus follow-up remain controversial and still not properly established, persisting a surgical overtreatment rate that can achieve $80 \%(13,14)$. In our 40 studied patients, only 15 had residual disease, thus $63 \%$ of our population was "cured" at colonoscopy. Contrarily to other studies (1315) none of the followed-up patients presented recurrent disease, probably in relationship with the small number of patients included in this group and an associated selection bias, since this group had only one patient with risk factor for locoregional disease (undetermined margins). 
Table II. Outcomes according to patients and tumors characteristics

\begin{tabular}{|c|c|c|c|c|c|c|c|}
\hline \multirow[b]{2}{*}{ Variables } & \multirow[b]{2}{*}{$n$} & \multicolumn{3}{|c|}{ Wall disease } & \multicolumn{3}{|c|}{ Lymph node metastasis } \\
\hline & & Absent & Present & $p$ value & Absent & Present & $p$ value \\
\hline Polyp location & & & & 0.132 & & & 0.316 \\
\hline Right colon & 6 & 4 & 2 & & 6 & 0 & \\
\hline Left colon & 22 & 16 & 6 & & 18 & 4 & \\
\hline Rectum & 12 & 10 & 2 & & 9 & 3 & \\
\hline Polyp configuration & & & & 0.034 & & & 0.094 \\
\hline Polypoid & 16 & 15 & 1 & & 11 & 5 & \\
\hline Non-polypoid & 24 & 15 & 9 & & 22 & 2 & \\
\hline Size & & & & 0.356 & & & 0.495 \\
\hline$<20 \mathrm{~mm}$ & 13 & 13 & 2 & & 12 & 1 & \\
\hline $20-39 \mathrm{~mm}$ & 22 & 17 & 5 & & 17 & 5 & \\
\hline$>39 \mathrm{~mm}$ & 4 & 2 & 2 & & 3 & 1 & \\
\hline Resection & & & & 0.135 & & & 0.392 \\
\hline En bloc & 25 & 21 & 4 & & 22 & 3 & \\
\hline Piecemeal & 15 & 9 & 6 & & 11 & 4 & \\
\hline Differentiation & & & & 0.018 & & & 0.462 \\
\hline Well & 32 & 24 & 8 & & 27 & 5 & \\
\hline Moderate & 6 & 6 & 0 & & 4 & 2 & \\
\hline Poorly & 2 & 0 & 2 & & 2 & 0 & \\
\hline Margin status & & & & 0.017 & & & 0.533 \\
\hline Complete & 16 & 16 & 0 & & 14 & 2 & \\
\hline Incomplete & 24 & 14 & 10 & & 19 & 5 & \\
\hline Lymphovascular invasion & & & & 0.278 & & & 0.332 \\
\hline Absent & 33 & 23 & 10 & & 28 & 5 & \\
\hline Present & 7 & 7 & 0 & & 5 & 2 & \\
\hline
\end{tabular}

Table III. Outcomes according to risk factors besides submucosal invasion

\begin{tabular}{|c|c|c|c|c|c|c|c|c|}
\hline \multirow[t]{2}{*}{ Risk factors } & \multirow[t]{2}{*}{$n$} & \multicolumn{2}{|c|}{ Treatment options } & \multicolumn{4}{|c|}{ Outcomes } & \multirow[t]{2}{*}{$p$ value } \\
\hline & & $\begin{array}{l}\text { Surgical } \\
\text { resection }\end{array}$ & Follow up & LNM & $\begin{array}{c}\text { Wall } \\
\text { disease }\end{array}$ & $\begin{array}{l}\text { Wall disease } \\
+ \text { LNM }\end{array}$ & $\begin{array}{c}\text { Global } \\
\text { locoregional } \\
\text { disease (\%) }\end{array}$ & \\
\hline One risk factor & & & & & & & & 0.008 \\
\hline Incomplete margins & 18 & 17 & 1 & 2 & 7 & 2 & 57.9 & \\
\hline Angiolymphatic invasion & 3 & 3 & 0 & 1 & 0 & 0 & 33.3 & \\
\hline Poor differentiation & 0 & 0 & 0 & 0 & 0 & 0 & 0.0 & \\
\hline Two risk factors & & & & & & & & 0.63 \\
\hline $\begin{array}{l}\text { Incomplete margins + } \\
\text { Angiolymphatic invasion }\end{array}$ & 4 & 4 & 0 & 1 & 0 & 0 & 25.0 & \\
\hline $\begin{array}{l}\text { Incomplete margins + } \\
\text { Poor differentiation }\end{array}$ & 2 & 2 & 0 & 0 & 2 & 0 & 100.0 & \\
\hline Any risk factor & & & & & & & & 0.01 \\
\hline $\begin{array}{l}\text { Incomplete margins or } \\
\text { angiolymphatic invasion } \\
\text { or poor differentiation }\end{array}$ & 27 & 26 & 1 & 4 & 8 & 2 & 51.9 & \\
\hline No risk factor & 13 & 5 & 8 & 1 & 0 & 0 & 7.7 & 0.01 \\
\hline
\end{tabular}


Table IV. Patients surgically resected by defect indication $(n=22)$

\begin{tabular}{lccc}
\hline & $\begin{array}{c}\text { Rectum } \\
(n=7)\end{array}$ & $\begin{array}{c}\text { Colon } \\
(n=15)\end{array}$ & $\begin{array}{c}\text { No residual } \\
\text { disease (\%) }\end{array}$ \\
\hline $\begin{array}{l}\text { Incomplete margins } \\
(n=17)\end{array}$ & $1 / 5$ & $6 / 12$ & $41.2 \%$ \\
$\begin{array}{l}\text { En bloc resection without } \\
\text { depth assessment }(n=5)\end{array}$ & $2 / 2$ & $2 / 3$ & $80 \%$ \\
Total $(\%)$ & $42.9 \%$ & $53 \%$ & $50 \%$ \\
\hline
\end{tabular}

The possible presence of LNM is an important and enigmatic aspect, its incidence is reported between 6.6 to $14.4 \%(12,13,18,19)$ in agreement with our calculated rate of $17.5 \%$ LNM. For more than 20 years investigators have searched for its determinants. The classical associated risk factors are depth (Sm3) submucosal invasion, poor differentiation, lymphovascular invasion, and tumor budding (20-23). Radical oncologic surgery is recommended for patients with any of the previous factors (14). In our analysis, as would be expected, we were not able to establish significant associations in this field. In fact, besides the sample limitation of our study we also could not incorporate in analysis any information related to depth of submucosal invasion or tumor budding. Regarding lymphovascular invasion, usually assumed as an important independent factor, we found that from the 7 patients with lymphovascular invasion only 2 had LNM, furthermore lymphovascular invasion was not seen in 5 of the 7 patients with LNM. This is congruent with other studies (13) and stresses the possibility of other factors involved, as well as the limited sensitivity, specificity, and difficult identification of lymphovascular invasion in small, fragmented, with extraction artifacts specimens. A recent exhaustive study on this topic demonstrated that the histopathologic factors for LNM in T1 colorectal cancers are: Grade 3 , angiolymphatic invasion, budding and the absence of background adenoma (18). Suh et al. did not find a significant relationship between LNM and depth of submucosal invasion, indicating the need for further evaluation in this area. Furthermore, in the largest study comparing the long-term outcomes for patients with submucosal invasive CCR, none of the classical risk factors were associated with recurrence (24). Instead, the risk for local recurrence was significantly higher in high-risk patients (incomplete resection, poor differentiation, vascular invasion, depth of submucosal invasion more than $1,000 \mu$ ) with submucosal rectal cancer than in patients with submucosal colon cancer when treated only with endoscopic resection. In another study the immunohistochemical expression pattern of several proteins in resected malignant polyps was also not associated with residual or recurrent disease (23). Thus there is a clear need for further evaluation in this area.

Besides LNM, other recognized oncologic outcome is wall residual disease, in this case the accepted risk factor is the margin status. When the resection margin is involved, or is less than $1 \mathrm{~mm}$, the relapse ranges between 21 and $33 \%$ (25). Patients in whom margins could not be conclusively determined had the same incidence of residual disease as patients with positive margins (13). However, whether the requisite distance should be $>1,>2$, or $>3 \mathrm{~mm}$ or only a clear margin is still under debate $(21,25-27)$. In our analysis we found a $25 \%$ rate of local wall disease and the margin status showed to be an independent risk factor for that, mostly in sessile lesions that are our main group, in agreement with earlier studies as Hassan et al. pointed out $(22,28,29)$. Polyp configuration, differentiation and margin status were also statistically relevant for wall disease. This point is mainly related with technical aspects, like piecemeal resection or poor specimen orientation, so also here there is space for improvement in resection approach and specimen processing.

When evaluating the available risk factors for residual disease (incomplete margins, lymphovascular invasion and poor differentiation), in both operated and non-operated patients, and the resultant outcomes we verified that patients with any of those risk factors had a significant risk for locoregional disease. By opposite its absence is strongly associated with a decreased risk, strengthening the idea that submucosal invasion itself is not a sufficient indication for subsequent surgery.

During the analysis we verified that 22 of the operated patients underwent surgical approach by defect of information -cases with inadequate margins evaluation (intercepted and undetermined) and cases resected en bloc lacking depth submucosal assessment- without any additional risk factor. Half of these surgeries were unnecessary as no residual disease was detected, this was even higher $(80 \%)$ when considering the cases which only lack the depth invasion assessment, in those 5 cases only one had residual disease (LNM). This is in accord with initial studies stating $15-20 \%$ potential risk for LNM in submucosally invasive cancers. From the recognized intrinsic tumors' properties associated with this, only depth and budding evaluation is missing. The point here is that besides patients having the current associated risk factors who may be undergoing unnecessary operations as some Korean authors described $(14,18)$, we detect that $50 \%$ of our patients undergone unnecessary operations preventively by defect information and inadequate evaluation.

The decision whether to perform an endoscopic resection should be individualized. Size and sessile or flat morphology of the polyp are associated with incomplete endoscopic resection (30). To our knowledge there is no study stressing, what we believe to be a frequent western countries' problem, related to poor endoscopic experience in ESD, the spread use of piecemeal resection in larger lesions, and with the poor experience of pathologists in evaluating submucosal behaviour of tumors without the complete wall specimen. We recognize the long learning curve on ESD, but these results justify some efforts 
as is being done for early gastric cancer. The rectum is a safe and easier place for beginners (31-33), additionally it is the origin of significant surgical complications as we described, thus avoiding unnecessary morbidity would be highly valuable. This would also allow an immediate and adequate orientation of specimen and a better evaluation of tumor architecture, depth, lymphovascular and perineural invasion, budding, vertical and horizontal margins, and a consequent increased experience of our pathology colleagues (34). Another important aspect is the characterization of lesions before endoscopic resection improving suspicious of invasion. Sometimes macroscopic appearance do not preclude a piecemeal approach, furthermore, smaller lesions are frequently approached in a simplistic manner using snare without submucosal injection, precluding adequate deep evaluation even in en bloc resections. New technologies on endoscopic image, as magnifying chromoendoscopy and narrow band imaging, will probably improve resection approach criteria $(35,36)$.

The limitations of this study were small sample size, which can influence the prevalence of residual or recurrent disease after endoscopic resection, its retrospective design and some points of the histologic evaluation. However our aim was not only the detection of risk factors, we knew from the beginning that these predictors are being exhaustively assessed in other studies, and that we do not have regularly some of those for clinical decision. We aimed to evaluate our real-life experience and consequently infer areas of improvement. In order to reduce overtreatment with surgery and its complications, it's crucial an enhance in endoscopic pre-histological diagnosis of invasiveness, improve mucosal resection and histologic evaluation (37).

In conclusion, we corroborate other studies pointing out the need for surgery in the presence of any risk factor versus cautious follow-up in case of no risk factors. Moreover we demonstrated that a significant proportion of patients have been unnecessarily operated due to technical aspects that can be improved. Furthermore, these improvements would be safely introduced for rectal lesions, precluding the significant surgical morbidity in this area.

\section{REFERENCES}

1. Takayama T, Katsuki S, Takahashi Y, Ohi M, Nojiri S, Sakamaki S, et al. Aberrant crypt foci of the colon as precursors of adenoma and cancer. N Engl J Med 1998;339:1277.

2. Grady WM, Carethers JM. Genomic and epigenetic instability in colorectal cancer pathogenesis. Gastroenterology 2008;135:1079-99.

3. Lieberman DA, Rex DK, Winawer SJ, Giardiello FM, Johnson DA, Levin TR. Guidelines for colonoscopy surveillance after screening and polypectomy: A consensus update by the US Multi-Society Task Force on Colorectal Cancer. Gastroenterology 2012;143:844-57.

4. Kedia P, Waye JD. Routine and advanced polypectomy techniques. Curr Gastroenterol Rep 2011;13:506-11.

5. Chandrasekhara V, Ginsberg GG. Endoscopic mucosal resection: not your father's polypectomy anymore. Gastroenterology 2011;141:42-9.

6. Bujanda L, Cosme A, Gil I, Arenas-Mirave JI. Malignant colorectal polyps. World J Gastroenterol 2010;16:3103-11.
7. Saito Y, Uraoka T, Yamaguchi Y, Hotta K, Sakamoto N, Ikematsu H, et al. A prospective, multicenterstudy of 1111 colorectal endoscopic submucosal dissections (with video). Gastrointest Endosc 2010;72:1217-25.

8. Saito Y, Fukuzawa M, Matsuda T, Fukunaga S, Sakamoto T, Uraoka $\mathrm{T}$, et al. Clinical outcome of endoscopic submucosal dissection versus endoscopic mucosal resection of large colorectal tumors as determined by curative resection. Surg Endosc 2010;24:343-52.

9. Cranley JP, Petras RE, Carey WD, Paradis K, Sivak MV. When is endoscopic polypectomy adequate therapy for colonic polyps containing invasive carcinoma? Gastroenterology 1986;91:419-27.

10. Ramírez M, Schierling S, Papaconstantinou HT, Thomas JS. Management of the Malignant Polyp. Clin Colon Rectal Surg 2008:286-90.

11. Compton CC, Greene FL. The staging of colorectal cancer: 2004 and beyond. CA Cancer J Clin 2004;54:295-308.

12. Risio M, Fiocca R. Malignant adenoma: Diagnosis, staging, risk factors, lymph node involvement and problems of sampling. Tech Coloproctol 2004;8:253-6.

13. Butte JM, Tang P, Gonen M, Shia J, Schattner M, Nash GM, et al. Rate of residual disease after complete endoscopic resection of malignant colonic polyp. Dis Colon Rectum 2012;55:122-7.

14. Choi DH, Sohn DK, Chang HJ, Lim SB, Choi HS, Jeong SY. Indications for subsequent surgery after endoscopic resection of submucosally invasive colorectal carcinoma: A prospective cohort study. Dis Colon Rectum 2009;52:438-45.

15. Compton CC, Fielding LP, Burgart LJ, Conley B, Cooper HS, Hamilton SR, et al. Prognostic factors in colorectal cancer. Arch Pathol Lab Med 2000;124:979-94.

16. The Paris endoscopic classification of superficial neoplastic lesions: Esophagus, stomach, and colon: November 30 to December 1, 2002. Gastrointest Endosc 2003;58:S3-S43.

17. Kikuchi R, Takano M, Takagi K, Fujimoto N, Nozaki R, Fujiyoshi T, et al. Management of early invasive colorectal cancer. Risk of recurrence and clinical guidelines. Dis Colon Rectum 1995;38:1286-95.

18. Suh JH, Han KS, Kim BC, Hong CW, Sohn DK, Chang HJ, et al. Predictors for lymph node metastasis in T1 colorectal cancer. Endoscopy 2012;44:590-5.

19. Sung CM, Hsu CM, Hsu JT, Yeh TS, Lin CJ, Chen TC, et al. Predictive factors for lymph node metastasis in early gastric cancer. World $\mathrm{J}$ Gastroenterol 2010;16:5252-6.

20. Cooper HS. Pathologic issues in the treatment of endoscopically removed malignant colorectal polyps. J Natl Compr Canc Netw 2007;5:991-6.

21. Ueno H, Mochizuki H, Hashiguchi Y, Shimazaki H, Aida S, Hase K, et al. Risk factors for an adverse outcome in early invasive colorectal carcinoma. Gastroenterology 2004;127:385-94.

22. Hassan C, Zullo A, Risio M, Rossini FP, Morini S. Histologic risk factors and clinical outcome in colorectal malignant polyp: A pooled-data analysis. Dis Colon Rectum 2005;48:1588-96.

23. Cubiella J, Arias MD, Penin MC, Quintas P, Couto I, Cobian C, et al. Immunohistochemical alterations in invasive adenocarcinoma in endoscopically resected adenoma and factors associated with risk of residual or recurrent disease. Colorectal Dis 2012;14:e587-94.

24. Ikematsu H, Yoda Y, Matsuda T, Yamaguchi Y, Hotta K, Kobayashi $\mathrm{N}$, et al. Long-term outcomes after resection for submucosal invasive colorectal cancers. Gastroenterology 2013;144:551-9.

25. Cooper HS, Deppisch LM, Gourley WK, Kahn EI, Lev R, Manley PN, et al. Endoscopically removed malignant colorectal polyps: Clinicopathologic correlations. Gastroenterology 1995;108:1657-65.

26. Volk EE, Goldblum JR, Petras RE, Carey WD, Fazio VW. Management and outcome of patients with invasive carcinoma arising in colorectal polyps. Gastroenterology 1995;109:1801-7.

27. Seitz U, Bohnacker S, Seewald S. Is endoscopic polypectomy an adequate therapy for malignant colorectal adenomas? Presentation of 114 patients and review of the literature. Dis Colon Rectum 2004;47:1789-96.

28. Kawamura YJ, Sugamata Y, Yoshino K, Abo Y, Nara S, Sumita T, et al. Endoscopic resection for submucosally invasive colorectal cancer: is it feasible? Surg Endosc 1999;13:224-7.

29. Hackelsberger A, Frühmorgen P, Weiler H, Heller T, Seeliger H, Junghanns K. Endoscopic polypectomy and management of colorectal adenomas with invasive carcinoma. Endoscopy 1995;27:153-8.

30. QuintasP, Cubiella J, Couto I, Bujanda L, Cobain C, Castro I, et al. Factors associated with complete endoscopic resection of an inva- 
sive adenocarcinoma in a colorectal adenoma. Rev Esp Enferm Dig 2012;104:524-9.

31. Matsui N, Akahoshi K, Nakamura K, Ihara E, Kita H. Endoscopic submucosal dissection for removal of superficial gastrointestinal neoplasms: A technical review. World J Gastrointest Endosc 2012;4:123-36.

32. Uraoka T, Saito Y, Yahagi N. What are the latest developments in colorectal endoscopic submucosal dissection? World J Gastrointest Endosc 2012;4:296-300.

33. Repici A, Hassan C, Pagano N, Rando G, Romeo F, Spaggiari P. High efficacy of endoscopic submucosal dissection for rectal laterally spreading tumors larger than $3 \mathrm{~cm}$. Gastrointest Endosc 2013;77:96-101.

34. Compton CC. Updated protocol for the examination of specimens from patients with carcinomas of the colon and rectum, excluding carcinoid tumors, lymphomas, sarcomas, and tumors of the vermiform appendix. Arch Pathol Lab Med 2000;124:1016-25.

35. Matsuda T, Fujii T, Saito Y, Nakajima T, Uraoka T, Kobayashi N, et al. Efficacy of the invasive/non-invasive pattern by magnifying chromoendoscopy to estimate the depth of invasion of early colorectal neoplasms. Am J Gastroenterol 2008;11:2700-6.

36. Ikematsu H, Matsuda T, Emura F, Saito Y, Uraoka T, Fu KI, et al. Efficacy of capillary pattern type IIIA/IIIB by magnifying narrow band imaging for estimating depth of invasion of early colorectal neoplasms. BMC Gastroenterol 2010;10:33.

37. Alexander S, Bourke MJ, Williams SJ, Bailey A, Co J. EMR of large, sessile, sporadic nonampullary duodenal adenomas: technical aspects and long-term outcome (with videos). Gastrointest Endosc 2009;69:66-73. 